\title{
MILITARY SURGERY IN 1861 AND IN 1918
}

\author{
By Major W. W. Keen, M.D. \\ Medical Corps, U. S. A.; Emeritus Professor of Surgery, Jefferson \\ Medical College, Philadelphia.
}

The fundamental difference between the surgical conditions during the Civil War (1861-65) and the present World War (191418) is our ignorance in 1861 and the enormous increase in our knowledge since that date. Between these two dates is a veritable chasm of ignorance which we can only appreciate when we peer over its edge and discover how broad and deep it is. Doubtless in another half century our knowledge will have again outstripped our present knowledge as far as our present knowledge exceeds that of fifty years ago.

What has filled up and finally obliterated this chasm? Clinical observation has done much but research, and chiefly experimental research, has done far more. In chemistry and in physics the chief advances in fifty years have been made by experimental research. In biology and its subdivision-medicine-the same is equally true.

We had obtained the precious gift of anesthesia in 1846, so that surgery was robbed of all pain during operations. Largely as a result of this abolition of pain, instead of three capital operations in a month, as at the Massachusetts General Hospital during the five years preceding 1846 , today an active hospital in civil life will report fifteen or twenty in a single day-four, five, or six thousand operations in a year instead of only thirty-six! The operations in our military hospitals in France are almost numberless.

\section{The Advent of Bacteriology}

But while anesthesia banished pain it had no influence on the terrible mortality following operations-often even the simplest ones.' It was reserved especially for Pasteur and Lister to triumph over death. Their researches pointed out the way and the method. Pasteur's researches only won gradual assent in the late 60's and early 70's. Lister's first paper on antiseptic surgery was not pub- 
lished until 1867, two years after the close of the Civil War, and his views were not generally accepted till the late 70's.

In the Civil War we knew absolutely nothing of "germs." Bacteriology-the youngest and greatest science to aid in this conquest of death-did not exist! It is undoubtedly the most important discovery ever made in pathology if not in all medicine. Yet even today when bacteriology is as demonstrably true as astronomy or chemistry, the opponents of research deny its discoveries and decry its methods. They even declare that germs do not produce any disease. They even deny the existence of typhoid fever as a disease!

As early as 1850 Davaine in France, in examining the blood of animals dead of anthrax, discovered certain little rods-"bacilli" in Latin, "bacteria" in Greek. Their presence was noted merely as a curious fact; but their significance, their causative relation to anthrax, was not even suspected. Repeated observations, however, showed that they were always found in the blood of animals dying of anthrax. When blood containing these little rods was injected into healthy animals, anthrax, and no other disease, always followed. The relation between these little rods and anthrax was finally and fully established.

As research proceeded, other germs were always found in other diseases and their causal relations were established in the same way. Year by year additional germs were discovered and by 1884 they had been classified and differentiated. In that year the word "bacteriology" was first used to indicate the science dealing with all classes of such germs. Not all are little rods. Some are small globular bodies ("cocci," i.e., "berries"), others of spiral shape like a corkscrew ("spirochetes"); but the Greek word "bacterium" (plural "bacteria") has been extended in its meaning to include all these different physical forms while the Latin word "bacillus" (plural "bacilli") has been reserved for those which are strictly speaking little rods, some straight, others more or less curved.

Many bacteria are "good" bacteria which disintegrate rocks and originate and add to the fertility of the soil; other harmless forms simply cause putrefaction; still others, however, are the cause of diseases, each the cause of its own disease and no other. These are known as "pathogenic" or "disease producing" bacteria. Some of them are among the deadliest enemies of the human race, 
e.g., the bacilli of tuberculosis, of the plague, of tetanus or lockjaw, of gas gangrene. Other bacteria produce pneumonia, cerebro-spinal meningitis, leprosy, cholera; infantile paralysis, etc.

Remember that bacteria lurk everywhere-in the air, on every physical object such as clothing, furniture, surgical instruments and dressings, on the skin of the patient, the doctor and the nurse, especially under the finger nails, unless all are "sterilized"-that is unless the bacteria on them are all destroyed. The means by which they are killed are either chemical (carbolic acid, corrosive sublimate, etc.) or by heat, i.e., boiling or steaming for a certain length of time and at a certain high temperature.

\section{The Cause and Cure of Tetanus}

Another and perhaps the most dangerous place in which these bacteria flourish-what might be called their favorite home-is in the intestines of man and animals. Many, e.g., the bacillus of tetanus, exist normally in the intestines of horses and yet the horses are in perfect health. But if a horse be wounded and the bacilli of tetanus get into the wound and multiply, then he will die just as would a man into whose wound these bacilli gain access.

Hence it can be seen that on cultivated land over which horses, cattle and other lower animals and man himself have roamed, the soil is deeply infected with these fecal bacteria. France and Flanders have been cultivated and manured for 2,000 years and it is no wonder therefore that it is. perhaps the most dangerous soil in the world. The almost virgin fields of battle during the Civil War held few bacteria and hence tetanus was not common though it was deadly, killing nine out of every ten victims. In the early days of the present World War it was a terrible scourge and took a fearful toll of lives. Exact figures can only be given after the war is over.

Fortunately, before the great war began, experimental research had discovered the tetanus antitoxin. As soon as there was enough of it for the huge numbers of the wounded, its ravages were checked. Few now die from lockjaw because every wounded man receives an injection of the antitoxin at the earliest possible moment. But those poor fellows who lie for hours or even days in "No-Man's Land" often receive the protective serum too late and, therefore, often perish. As soon as the poison has combined with the nerve cells no amount of the antitoxin will do the least good. Every hour of delay means a life lost. 
It can easily be understood how and why we surgeons in 186165 , utterly unaware of bacteria and their dangers, in our ignorant innocence committed grievous mistakes which nearly always imperilled life and often actually caused death. May le bon Dieu forgive us our sins of ignorance. We operated in old blood-stained and often pus-stained coats, the veterans of a hundred fights. We operated with clean hands in the social sense, but they were undisinfected hands. To the surgeon, the spotless hands of a bride are dirty. We used undisinfected instruments from undisinfected plush-lined cases, and still worse, used marine sponges which had been used in prior pus cases and had been only washed in tap water. If a sponge or an instrument fell on the floor it was washed and squeezed in a basin of tap water and used as if it were clean.

Our silk to tie blood vessels was undisinfected. One end was left long hanging out of the wound and after three or four days was daily pulled upon to see if the loop on the blood vessel had rotted loose. When it came away, if a blood clot had formed and closed the blood vessel, well and good; if no such clot had formed then a dangerous "secondary" hemorrhage followed and not seldom was fatal. The silk with which we sewed up all wounds was undisinfected. If there was any difficulty in threading the needle we moistened it with (as we now know) bacteria-laden saliva, and rolled it between bacteria-infected fingers. We dressed the wounds with clean but undisinfected sheets, shirts, tablecloths, or other old soft linen rescued from the family ragbag. We had no sterilized gauze dressing, no gauze sponges.

At the Jefferson Medical College, Gross and Pancoast operated on the same table on which the cadaver was demonstrated by the professor of anatomy. Often the surgical assistants spent the morning in the dissecting room and at noon were assisting at operations or attending obstetrical cases.

In the adjoining building we had two small hospital wards of five or six beds each for men and women, for the most serious cases. Is it any wonder that when my teacher of surgery, Professor Gross, wanted pus to illustrate his lecture he would turn to the orderly and say, "Tomorrow, Hughey, I am going to lecture on suppuration. Go over to the hospital in the morning and get me a half tumblerful of pus!" And he always got it. Pus was always on tap. What was far more deplorable, erysipelas, tetanus, blood-poison- 
ing, hospital gangrene were also "on tap." Death was ever peering over the shoulder of the surgeon, watching for his victim.

In the Civil War, lockjaw was not frequent but it killed ninety out of one hundred patients; compound fractures killed two out of every three; amputations averaged over 50 per cent mortality. Until the total statistics of the great war are collected-a work of years-we can only quote individual statistics. Of 1,000 cases of tetanus in the base hospitals in England, the mortality was only 40 per cent. . Among these 1,000 , forty had not received the antitoxin and of them 80 per cent died. Of the 960 cases which had received the antitoxin only 38.8 per cent died,-i.e., less than onehalf of the former.

Only 25 per cent of the cases of compound fractures are now fatal instead of 66 per cent as in the ' 60 's. Four out of five amputations are due to infection. Our victory over infection is the reason for the greatly diminished number of amputations in the present war. Moreover, the mortality of amputations in our armies is low; in some series every one has recovered. Of the wounded, $80 \mathrm{per}$ cent are soon able to return to the fighting lines.

In open wounds in our armies in 1861, as we knew nothing about antiseptics (and therefore used none) maggots, as large as chestnut worms, abounded in the summer. While utterly disgusting they did little or no harm. Now these are never seen.

Today how utterly different are our present methods. So rapid has been the progress, even in the last two years, that Harvey Cushing, writing me recently from France, said, "Even 1916 was another world."

\section{Importance of Disinfection IN Wounds}

As in civil surgery, the skin in the area of operation is carefully disinfected; beyond this area everything is covered with disinfected sheets or towels. The surgeon, every assistant and every nurse wears disinfected gowns and disinfected rubber gloves. Every instrument, dressing, needle and the silk and catgut used for ligatures to tie blood vessels and to sew up wounds are all sterilized. For years in my clinic, just before I began the first operation an assistant from the bacteriological laboratory took a scraping from the back and palm of the hands and from under the finger nails of myself and every assistant and nurse, to discover if any of us 
had failed to have completely sterile hands and finger nails. I am glad to add that it was rare to find anyone at fault. Had anyone been repeatedly delinquent, warning or even dismissal would have followed.

During an operation, to touch anything not disinfected was anathema maranatha. Soon a surgical habit or instinct is acquired and avoidance of such contact becomes automatic. Fortunately the "septic glances" alleged to have been darted at the wound from a distance by one surgical cynic did no harm.

All ligatures on blood vessels are now cut off short and in non-infected cases the wound is immediately closed. The ligatures are absorbed and never heard from. Secondary hemorrhage is almost unknown. In one night after Gettysburg, I had five cases of secondary hemorrhage. From 1876, when I adopted the antiseptic method, till today I have not seen five other cases. In civil surgery, for years prior to 1914, practically all sterile wounds healed within a few days.

But in this World War, conditions in 1918 are far different not only from those of the Civil War and from those immediately before the war, but even from those from 1914 to 1916 .

The present war is waged on and in densely infected soil; the wounds are caused by high explosives which hurl many irregular fragments with unimagined velocity; wounds are often multiple, even up to one hundred simultaneous wounds; the tissues are horribly lacerated and devitalized; fragments of the missile and of the dirty, muddy and highly infected clothing are often driven deep into the tissues; all these elements have conspired to develop an unprecedented riot of infection. Every wound is infected and with an intensity utterly unknown prior to 1914 either in civil or military surgery. The efforts to control infection by the means in ordinary use almost entirely failed during the first two years of the war. Tetanus, gas gangrene, blood poisoning and other infections seemed unconquerable for a time.

But research has won the victory. Lister's surgical principles have been at last even more firmly established than ever. The chemist and the bacteriologist are now constantly associated with the surgeon and together they have often snatched the crown from the brow of death. Carrel and others have shown that for, say the first six, sometimes even for the first twelve hours after a wound 
has been inflicted, the bacteria-even the most dangerous-are localized on the tissues lining the wound and especially near any retained clothing or fragment of shell. The wound is "contaminated" but not yet deeply "infected."

If the wounded can be brought to the surgeon within these few golden hours, even after very severe wounds, two out of three can be saved. But to effect this, first of all the most perfect aseptic care must be given; all missiles and especially all dirty and infected clothing must be removed, in finding which the X-rays are of the utmost service; by the knife the wound is opened to all its ultimate pockets and recesses, and the tissues lining the entire wound are cut away. With this removal of the tissues covered with bacteria, all the adjacent tissues which have been practically killed and devitalized by the fierce impact of the missile must also be removed. Then the wound can be closed at once and will heal immediately. The knife in such cases is by far the best antiseptic. The few bacteria left are destroyed by the cells and fluids of the body.

\section{The Carrel-Dakin Method}

But in those unfortunates who do not reach surgical aid promptly, even though the foreign bodies and the devitalized tissues be removed too often, the wounds by that time are so deeply infected that primary healing cannot be secured and other means of treatment must be used. Dakin, an English physiological chemist, now residing in America has found by research the means of depriving the cheap ordinary bleaching powder (sodium-hypochlorite) of its noxious properties; and Carrel, by prior years of work in the Rockefeller Institute and in France for four years, has devised a means for distributing this best disinfectant to even the deepest parts of the wound in a constant stream. The bacteria are rapidly destroyed. Every second day the bacteriologist examines the discharges from the wound and counts the number of bacteria found by his microscope. When they have practically disappeared the surgeon can then close the wound. Out of four hundred such wounds closed in Carrel's hospital at Compiègne-now destroyed by the barbarous Huns - there were only six failures.

There are several other methods of treatment which are used by many surgeons and with excellent results, but the lack of space compels me to pass them by. Of course very many of the wounded 
are so mutilated that death is inevitable and the surgeon can only soothe the pain or possibly postpone the final result.

\section{The Sanitation of Today}

Sanitation fifty years ago was crude and unsatisfactory as compared with that of today. The chief reason for this was that bacteriology was utterly unknown and that research had not discovered any of the antitoxins nor the rôle of the insect world in spreading disease.

The opponents of research insist that "sanitation" is practically the only means by which the death rate has been lowered. It is amusing to realize that in insisting on sanitation they are commending and insisting on bacteriology, their bete noire. Engineering and chemistry have done very much to develop modern sanitation, but bacteriology has been the most important factor in this development. That pure water and pure milk have lessened typhoid is perfectly true. But how do we know pure water when we see it? Only by testing the water supply bacteriologically every week. Only a bacteriologist can decide whether milk is dangerous or safe.

In 1861 we were wholly ignorant of the fact that the mosquito, and only the mosquito, spreads yellow fever and malaria; and of the rôle of the fly in spreading typhoid fever by walking on the excreta of those sick of typhoid and then over our food and infecting it with the typhoid germs which we swallow with our food. We knew how disgusting and annoying were the louse and the flea, but we did not even suspect that the flea and the rat conspired to spread the bubonic plague, and that the louse was responsible for the deadly typhus and that serious and wholly new disease-trench fever.

Moreover, research has now provided us with antitoxins against typhoid, diphtheria, tetanus, cerebrospinal meningitis, and other diseases, and will provide us with still more.

\section{The Reduction and Control of Typhoid}

Typhoid has been banished from our army. When we recall the figures for the Civil War and the Spanish-American War in contrast with the present war, the American people should be infinitely grateful to the patient, persistent and much abused research workers in our laboratories for their humane and beneficent work.

The bacillus of typhoid was only discovered in 1880, fifteen years 
after the Civil War. During the Civil War there were 79,462 cases and 29,336 deaths from typhoid. In the Spanish-American War, out of 107,000 soldiers in our whole army, there were 20,738 cases and 1,580 deaths from typhoid. Every fifth man was attacked. Of the entire number of deaths during this short war, including both those from disease and from wounds 86 per cent were due to typhoid alone!

In the present war as in the case of tetanus, the use of the preventive antitoxin has enormously reduced the number of typhoid cases. The Germans had prepared many great hospitals for the confidently expected typhoid patients. Typhoid was conquered. These hospitals were never used for typhoid patients, but were devoted to other purposes.

The recruiting of our army was in the autumn of 1917 , the very season for typhoid, with men in numbers fifteen times as many as in the Spanish-American War, and in a period exceeding in length the whole duration of that war. The following figures have been furnished me by Surgeon General Gorgas:

In the entire army, numbering over $1,500,000$ men at the end of December, 1917 , there had been during the year 242 admissions to hospitals on account of typhoid fever, with 18 deaths. During the corresponding period in 1861, when the Northern Army was being mobilized, there were about 9,500 cases of typhoid fever with less than one-quarter of the strength of the present army with about 1,800 deaths.

Had the rate of the Civil War prevailed in 1917 there would have been 38,000 cases and 7,200 deaths, instead of 242 cases and 18 deaths. Had the rate of the Spanish-American War prevailed there would have been over 311,000 cases and 23,700 deaths instead of 242 cases and 18 deaths! In the annual reports of the surgeon generals of the army and navy this enormous and happy prevention of typhoid is attributed "almost in toto" to the antityphoid vaccination. In the British Army 99 per cent of the soldiers are vaccinated voluntarily.

During the past year, of the $1,500,000$ vaccinated men, about 9,000 were obliged to spend one or two days in hospitals on account of a moderate resulting fever following the vaccination. During that same year there was just oNe death ascribed to antityphoid vaccination-one death out of over 1,500,000 men-one fifteen thousandth part of one per cent! Yet the opponents of research have intimated that "thousands" of deaths have followed the anti- 
typhoid vaccination. Are not these figures an overwhelming testimony to its value and do they not prove the wisdom of making it compulsory in order to save the lives of our dear boys, and help win the war?

These same people have also asserted that the death rate in the army far exceeded that of our large cities. General Gorgas states that on the contrary statistics for men from 20 to 30 in our large cities show that the army death rate in July 1918 was only onethird of the urban death rate, i.e., 1.9 per thousand instead of 6.7 per thousand. It is time that these malicious mis-statements should cease.

Never in the history of the world have such splendid efforts been made to reconstruct and re-educate the inevitable wreckage of war, as are now effectively restoring the wounded and mutilated to happy social life and to self-support instead of abandoning them to idleness, poverty and despair. The dentists and surgeons reconstruct faces and jaws formerly considered absolutely hopeless. "The surgeons doing this facial work avail themselves of the services of artists, plaster modellers and sculptors. An accurate plaster cast of the present condition is used as a base on which a restoration is made in modelling clay by the sculptor. If good photographs of the man taken before his wound are available, they are of service to the sculptor." The orthopedic surgeons restore motion to apparently useless arms and legs, so that the man can be employed in gainful occupations and become partially and often wholly selfsupporting. Such work was unheard of in the Civil War. It is one of the real benefits to the credit side of the great war.

New Instruments of Precision and Methods of Diagnosis

I must compress into a few words what I have to say as to new instruments of precision and new methods of diagnosis which have been discovered since the Civil War.

It will surprise most of us to learn that there were practically no clinical thermometers in our armies in 1861-65. The first book ever written on the use of the thermometer in medicine was not published until 1869 -four years after the end of the Civil War. Imagine the plight of a surgeon, physician, obstetrician, or even of the mother of a family today without a clinical thermometer. Hemostatic forceps, retractors and dilators, now in constant use, were utterly unknown. The hypodermic syringe was so new that 
the number of army surgeons who had one in Civil War times probably did not exceed the number of one's fingers and quite surely not of fingers and toes together. The ophthalmoscope had been devised in 1851 but few and far between were those who could use it in our army ten years later. This was even more true of the laryngoscope, first devised in 1858.

Instruments for examining all the accessible hollow organs, the ear, the nose, the bronchial tubes in the interior of the lung, the stomach, bladder, ureter and kidney, were not so much as dreamed of fifty years ago. The chemistry and physics of the blood and the various devices to study the blood pressure were unknown. Now we can analyze the action of the heart, of its four cavities and its valves separately to the exact action of each during the 1/50th part of a second by the electrocardiograph.

The wonderful X-rays were discovered in 1895 and the apparatus for using them has been so much improved that now we can see the convolutions and the cavities in the brain. By mixing bismuth with the food and then tracing it from esophagus to rectum by the X-rays, we have learned much as to living anatomy and physiology, and can often diagnose cancer of the stomach or of the bowels, can see any foreign body either in the stomach or intestines and in the windpipe or the bronchial tubes. Chevalier Jackson, one of my colleagues at the Jefferson, has taught the world how to remove such foreign bodies from the air passages through the mouth instead of by a very dangerous cutting operation.

The surgery of the chest long lagged far behind that of the head and the abdomen because when the chest was opened the lung collapsed and breathing became embarrassed, or impossible, if both sides were opened. Now'Meltzer and Auer of the Rockefeller Institute have devised a method of anesthesia by pumping etherladen air into the lungs through a rubber tube introduced into the windpipe. This keeps up the respiration and we can now operate on all the organs in the chest as easily as we do on the contents of the abdomen.

"The road to the heart is only a little over an inch in a direct line," says Professor Frederic S. Lee, "but it has taken surgery nearly 2,400 years to travel it." The heart was first laid bare and sewed up for a stab wound twenty-one years ago (1897). Now this operation has been done hundreds of times and has saved the lives 
of about half of those operated upon. In this war, missiles have been removed from the interior of the heart and even from the large blood vessels.

Most of the improvements and the discoveries I have described and many others have been made in research laboratories and largely by men whose name and fame are unknown except to their professional colleagues. Their work has been marvelously successful and beneficent not only to man but to millions of the lower animals whose sufferings have been enormously diminished and whose lives have been saved-a combined humanitarian and economic gain which can hardly be estimated.

One striking instance of the value of experimental research as compared with observational and clinical research is the following:

Syphilis has been known and carefully studied for over four hundred years. It is one of the three great physical enemies of the human race, tuberculosis and alcohol being its sister scourges. In 1903 Metchnikoff of the Pasteur Institute in Paris first succeeded in inoculating the higher apes with the disease. Since then we have learned how to inoculate other animals. Only two years passed before bacteriologists discovered the germ which produced the disease. This enabled us to test any and every remedy, even the most dangerous, far too dangerous to be tested upon man. After five more years Ehrlich discovered a cure. This discovery rewarded a persistence and zeal the like of which has never been equaled. After six hundred and five successive failures, the six hundred and sixth was a success. Think of the labor required by each one of these six hundred and five failures and of the robust optimism which still continued the research!

In these seven years we learned more and accomplished more for the human race at large than in the preceding four centuries of intense clinical study. This discovery is one of the most beneficent ever made. Its use is far from being restricted to the sinners against law and morality. The number of its innocent victims is almost incalculable. Now we are masters of the situation; we have the whip-hand of this monster of suffering and shame.

Even in this very incomplete sketch what wonderful progress is revealed! Research has not yet ceased to give us better and better methods of coping with disease and death, and-thank God!-it never will cease so long as disease and death continue to afflict the human race. 